The philosophy about the subject in the auto poetic anthology of Borges

\title{
La filosofía en torno al sujeto en la auto antología poética de Borges
}

Javier Barraca Mairal

Universidad Rey Juan Carlos de Madrid javier.barraca@urjc.es

DOI: https://doi.org/10.15366/bp2021.27.023

Bajo Palabra. II Época. № 27. Pgs: 443-464

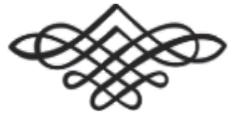


Recibido: 27/01/2020

Aprobado: 07/05/2021

\section{Resumen}

En este artículo, se reflexiona acerca de las relaciones establecidas entre filosofía y literatura, articuladas en torno al eje de la subjetividad, en la antología realizada por el propio Borges de la poesía que escribió entre 1923 y 1977. Se estudia, en esta obra concreta, el tema de las raíces del sujeto o de la identidad personal y sus hondos vínculos con la alteridad. Se pone en contacto su perspectiva con la de otros poetas y pensadores contemporáneos. Finalmente, se concluye que su esfuerzo se revela como una profunda búsqueda de la propia subjetividad gracias la creatividad. Otras claves borgianas en torno al sujeto se encuentran en su recurso a los diferentes niveles de la realidad, las relaciones intersubjetivas, el infinito y la gratitud.

Palabras clave: Borges, Filosofia, poesía, sujeto, identidad, alteridad.

\section{Abstract}

In this article, we reflect on the relationship between Philosophy and Literature, articulated around the axis of subjectivity, in Borges' own anthology of the poetry that he wrote between 1923 and 1977 . We study the theme of subject's roots, personal identity and alterity in this particular book. His perspective is brought into contact with that of other contemporary poets and thinkers. Finally, we conclude that his effort is revealed as a deep search for one's own subjectivity through creativity. Other Borgian keys about the subject are his resource of different levels of reality, relationships, infinity and gratitude.

Keywords: Borges, Philosophy, poetry, subject, identity, alterity. 
El tema de nuestra investigación: la filosofía en torno a la identidad en la auto antología poética de Borges.

EN EL MARCO DEL PENSAR CONTEMPORÁNEO, parece darse en determinados autores un cierto interés en torno a la cuestión de la subjetividad; esto, al menos, en el ámbito de la reflexión filosófica ${ }^{1}$. Ahora bien, pese a que lo literario nunca ha dejado de plantearse la pregunta acerca del sujeto, todavía cabe promover estudios que, partiendo de un enfoque filosófico y de una obra de creación específica, exploren esta confluencia y adviertan sendas fecundas con respecto a la subjetividad y la relación con los otros. Este es el caso de la peculiar poesía de Borges, que a causa de esto puede presentar hoy una renovada fertilidad en el asunto planteado.

La poesía de Borges constituye un universo de símbolos, significaciones y evocaciones lleno originalidad y, a la par, afín a su peculiar estilo, siempre característicamente personal ${ }^{2}$. Esto corresponde en parte con lo ocurrido en su esfera narrativa, y converge en ciertos rasgos con los de otros campos de su elaboración artística. Ahora bien, dentro de este singular micro-cosmos late una preocupación concreta digna de reflexión; se trata de la cuestión de la identidad personal, el núcleo mismo de la propia subjetividad. Dada, además, la particular intensidad que esta interrogación cobra en su obra poética, parece que esta supone un área de estudio de especial interés a la hora de abordar algunas de las notas de esta constante borgiana. En su poesía, la cuestión de la identidad adquiere una hondura de especial relevancia, por cuanto la concentración o densidad que el propio lenguaje poético conlleva contribuyen a acentuar su valor y resonancia.

Debido a lo precedente, se va a indagar en torno a este asunto concreto con la conciencia de que puede brindar luz a propósito de la subjetividad. El sujeto y sus avatares creativos más hondos, la compleja alianza del binomio identidad-alteridad, la persona y la relación, el yo y el otro, sobre la base de la humana vocación a la originalidad, se han convertido en el vértice de una reflexión que ha cobrado un peso innegable ${ }^{3}$. Ahora bien, no entenderemos aquí la creatividad respecto a la

${ }^{1}$ Cf. AA. VV., González Rodríguez-Arnáiz, G. (coordinador): Ética y subjetividad: lecturas de Emmanuel Lévinas, Madrid, Ed. Universidad Complutense, 1994.

2 Borges, J.L.: Poesía completa, Barcelona, Destino, 2009.

3 Ética y subjetividad: lecturas de Emmanuel Lévinas, op. cit. También: Ferrer, U., ¿Qué significa ser persona?, Madrid, Ed. Palabra, 2002. 
subjetividad a la manera extrema de ciertos de-constructivismos y constructivismos radicales del sujeto, que lo resuelven del todo a través de sus estructuras o dinamismos, como por ejemplo puedan postular posturas en parte semejantes a las de Judith Butler u otras líneas de pensamiento actuales, inspiradas en esto en Derrida o Foucault ${ }^{4}$.

Nos centraremos en cierta antología que Borges realizó de sus versos, en concreto la Antología poética 1923/19775. Esto, dado que, como él explicó en el prólogo, su criterio selectivo clave fue, para esta ocasión, el de su propio gusto personal; lo que, al abordar la indagación de su misma identidad, presenta aquí un interés especial. También, a causa de que dicha antología ofrece un área de encuentro entre poesía y filosofía de singular relevancia, y este constituye el campo de visión preciso de nuestro análisis. Por último, debido a que esta antología personal abarca un amplio arco de tiempo (1923-1977), 54 años de su creación literaria, y, asimismo, a que incluye algunos de los poemas que se han considerado más representativos, dentro de su producción, con respecto al asunto de la subjetividad (Poema de los dones, Ajedrez, La lluvia, El otro tigre, Una rosa y Milton, Laberinto, Las cosas, etc.) Para enmarcar este esfuerzo, en el contexto más amplio de la producción poética del autor, de sus hilos conductores y pautas fundamentales, remitimos a la síntesis que de ella realizó Viñas ${ }^{6}$.

\section{Filosofía y poesía en la antología poética de Borges}

LA PRESENCIA DE LO FILOSÓFICO en la poesía de Borges comporta diversos aspectos y registros. En primer lugar, lo hallamos en la materialidad de la cita constante del poeta a los pensadores más célebres. Los nombres de estos asoman, de modo continuo, entre sus versos. Esto va desde los pensadores clásicos, a otros más recientes. Así, por ejemplo, en el volumen que comentamos: Pitágoras, Zenón, Heráclito, Anaxágoras, Sócrates, Séneca; pero, también, Francis Bacon, Spinoza, Gracián, Locke, Hume, Schopenhauer, Nietzsche, etc. A este respecto, conviene notar que la antología da sus primeros pasos precisamente con un nombre propio, y que es el de un filósofo. En efecto, el prólogo del autor da comienzo a su recopilación con la frase: "A principios del siglo XVII, Francis Bacon...". Por cierto, lo que sigue es

\footnotetext{
${ }^{4}$ Cf. Azaovagh de la Rosa, Anisa, "Judith Butler y su precariedad metódica”, Madrid, en: Bajo Palabra: revista de Filosofía, época II, no22 (2019), pp. 147-170 (DOI: https://doi.org/10.15366/bp2019.22.007).

5 Borges, J. L.: Antología poética 1923/1977, Madrid, Alianza, 1981.

${ }^{6}$ Viñas Piquer, David: "Recorrido fugaz por la poesía de Borges”, Valparaíso, en Rev. Signos, v.32, n.45-46, pp. 57-70 (1999).
} 
una crítica a determinado abuso de la pretensión que se cita de este pensador, quien reivindicó la necesidad de que la historia integrara también a las artes y las ciencias. Esto, por cuanto Borges reprueba el que muchos se han excedido al reducir la literatura a mera historia o bibliografía, incurriendo en el historicismo y la sola erudición. Por otra parte, el poema que cierra el volumen lleva el filosófico título de "Las causas". Asimismo, entre el prólogo y el poema mencionado, se suceden otros que, en sus propias designaciones, contienen evidentes resonancias filosóficas. Esto sucede, por ejemplo, con los que siguen: "Llaneza", "Le regret d'Héraclite", "La noche cíclica", "Poema conjetural", "Everness", "Spinoza", "El laberinto", "Laberinto", "Ewigkeit", "Las cosas", "De que nada se sabe", "All Our Yesterdays", "Ein Traum", "La pesadilla", "Heráclito", "Signos", "Ni siquiera soy polvo", etc. Como puede verificarse, varios incluso tienen por título el nombre de un señalado filósofo (Heráclito, Spinoza).

En un registro más hondo, podemos advertir la presencia no sólo de los meros nombres sino de las ideas nucleares de algunos de estos filósofos, en el interior de los poemas borgianos. A este respecto, cabe destacar algunos tópicos filosóficos, especialmente reiterados e influyentes, en la obra del poeta que reseńamos. Entre ellos, merece en concreto la pena mencionar la idea del cambio permanente o cíclico en la naturaleza, el tiempo como dimensión intrínseca de la existencia humana, o la serena aceptación del infortunio y la mortalidad, etc. Por otro lado, Borges posee sus propias o genuinas concepciones filosóficas, y las expone sin poder evitarlo a lo largo de sus versos. Algunas de ellas, tienen una carga filosófica considerable, en cuanto a su profundidad y capacidad de sugestión. Entre las mismas, pueden sintéticamente recordarse: su interpretación de la existencia humana como un ejercicio de lectura y relectura inagotables, su singular hermenéutica del tiempo que funde presente, pasado y futuro en un continuo personal afectivo, su bosquejo del universo entero como un laberinto que es símbolo a descifrar en su enigmático significado, etc. A causa de todo esto, acaso cabría calificar su poesía como metafísica, al menos en cierto sentido.

\section{la identidad en la antología poética de Borges}

LA INTERROGACIÓN EN TORNO A LA PROPIA IDENTIDAD constituye uno de los hilos conductores de la literatura borgiana. Esta se encuentra en los diferentes campos sobre los que se proyecta el genio del autor ${ }^{7}$. La descubrimos en su cuentística, pero

7 Borges, J. L.: Obras completas, Buenos Aires, Emecé, IV vols., 2009. 
también en su labor crítica, en sus ensayos, en sus textos más autobiográficos, en su tarea como conocedor y transmisor de la literatura, etc. Ahora bien, esta cuestión alcanza en su poesía un valor peculiar. El motivo se halla, a la par, en la hondura y belleza que esta raíz cobra en sus composiciones poéticas. También, sus conferencias e intervenciones orales, sus clases y otras manifestaciones, como las entrevistas, prólogos, etc., registran asimismo esta constante temática, la del propio sujeto que se interroga en torno al núcleo de su ser. Desde luego, lo biográfico y autobiográfico se despliegan en el juego literario de nuestro escritor con prodigalidad. Para ello, entre otros recursos, este acude al desdoblamiento entre la experiencia contenida en el poema y la subjetividad misma del autor que la glosa o enuncia -en un gesto continuo de meta literatura o meta lenguaje-. Así, la antología da comienzo precisamente con un poema - "El sur"- que nos habla de las experiencias más genuinas e íntimas, vividas por el autor. De aquí, su estar poblado por la presencia de los seres que, en el contexto de su lugar de origen, habitan la memoria: patios, banco, estrellas, secreto aljibe, olores característicos, formas y presencias familiares, etc. Al fondo de estas primigenias vivencias, sentimos palpitar al sujeto de todas ellas, cual un centro presentido. En seguida, tras una breve composición, fundada en un detalle que impacta y queda grabado en el recuerdo -"Carnicería"-, sigue "Llaneza", poema en el que se nos hace ya clara la presencia del sujeto en torno del cual giran los versos concéntricamente, alguien -y no ya algo- del que se dice que es admitido, acogido por los que con él coexisten cercanamente ("/bien me conocen quienes aquí me rodean/"). A partir de estos primeros compases, la cuestión de la identidad se sucede ininterrumpidamente a través de la obra. Se diría cual un oleaje incesante, que fuera incrementándose o apaciguándose en su intensidad, según las variadas tonalidades y temas de los poemas; pero que se encuentra siempre latente, vivo y palpitando a la vera del lector.

\section{La identidad como búsqueda creadora en la poesía borgiana}

ACASO lo MÁs ORIGinal que, respecto a la identidad, plantea la específica conjunción de lo poético con lo filosófico, en Borges, radica en que esta se nos ofrece en la clave de una subjetividad que implica una búsqueda cargada de vínculos con la alteridad y desplegada desde la creatividad. Creatividad, alteridad y originalidad o identidad personal confluyen así en el autor, en la forma precisa de una búsqueda plena de belleza y profundidad. Esta senda en pos del eje subjetividad-alteridad ha sido, sin duda, transitada también, antes y después, por otros; si bien, en cada caso, la intersección de lo filosófico y lo artístico como nudo de la identidad, a 
través de la clave de la creatividad, reviste siempre peculiaridades y especificidades distintas, según los diversos autores y contextos ${ }^{8}$. Junto a lo precedente, otro signo característico que no deja nunca de acompañar a los poemas de Borges, se halla en cierta actitud ética de fondo, que se transparenta en dicho peregrinaje tras los evanescentes pasos de la identidad personal. En la voz borgiana vibra y tiembla un yo en sincera y comprometida busca de sí, a la par de una peculiar honestidad consigo, por parte del autor, una responsabilidad con el sí mismo o vocación más hondos y auténticos del poeta ${ }^{9}$. Esto conecta con la lectura de lo autobiográfico en Borges en tanto "ficcionalización", esa característica simbiosis entre lo real y lo imaginado, cuyo movimiento ininterrumpido oscila, cual péndulo, en la variable configuración de la propia obra, vida e identidad ${ }^{10}$. Sin embargo, a nuestro juicio, va mucho más allá de este extremo.

Tampoco cabe reducir esta singular búsqueda literaria a una imaginaria representación auto-biográfica, que se gestara a sí misma, ni viceversa. Esto, pues biografía y literatura, el poeta Borges enunciador y el Borges que aparece enunciado en sus poemas, permanecen como recíprocas solicitudes que el lector o hermeneuta acaso deseara aproximar demasiado pronto. De hecho, en su prólogo, el mismo autor pide que su poesía no sea decodificada en clave de una mera autobiografía implícita o velada. Ello conecta con la fértil forma de orientar la hermenéutica de lo artístico que postuló Gadamer, quien se pronunció a favor de una fecunda interpretación integradora del arte, a la par universal y personal, pero siempre vocacional, por cuanto todo lo artístico comporta, según este autor, una interpelación personal, enriquecedora de nuestra identidad. ${ }^{11}$ No es sólo, entonces, que Borges explore y juegue en torno de su propia identidad a través de diversas ficciones personales de la alteridad, adquiriendo la forma y roles de distintos personajes, tanto históricos como inventados, más o menos lejanos en el tiempo o en el espacio a él mismo. Esta exploración lúdica, emparentada con el drama o el teatro, ya se encuentra en otros egregios poetas, como Pessoa a través de sus conocidos heterónimos ${ }^{12}$. Borges opera, por su parte, algo distintivo: una fecunda y original transfiguración del sentido del sujeto, a través de sus diferentes niveles de

\footnotetext{
${ }^{8}$ Cf., como síntesis de algunas de estas búsquedas, en nuestro tiempo, en torno a la identidad personal: Barraca, J., Originalidad e identidad personal, Madrid, Ed. San Pablo, 2017.

9 Manuel Maceiras lee también la ética precisamente como este ejercicio de responsabilidad con la propia identidad personal y los otros, en sintonía con parte de la Filosofía de la subjetividad de autores como Lévinas o Ricoeur. Cf. Maceiras, M.: Identidad y responsabilidad, discurso de apertura del curso académico, Madrid, Universidad Complutense de Madrid, 1994.

${ }^{10}$ Cf. Iglesia, Anna María: "La poesía de Borges: una ficción autobiográfica”, Rev. Forma, vol. 2, pp. 69-81, 2013.

11 En este sentido preciso, cabe recordar, dentro del pensamiento hermenéutico de Gadamer, la recopilación: Gadamer, H. G., Estética y hermenéutica, Madrid, Tecnos, 1996.

12 Cf. Pessoa, F.: Fernando Pessoa. Poesía, Madrid, Ed. Alianza, 1983.
} 
experiencia y de encuentro con los otros, a lo largo de este original proceso creativo que resuena cual desarrollo identitario. Ya no es sólo que el autor busque la fecundidad, para el dinamismo de su subjetividad, de este curioso e incesante teatro de las identidades, reales o ficticias, representado tanto por la propia como por las de los otros... Alteridad e identidad, en la antología, se entretejen indisoluble e incansablemente, pues trenzan la urdimbre afectiva, intelectual y moral de ese intrincado manto que hilvanan juntos el yo y el tú, al modo en que lo han descrito los más perspicaces pensadores dialógicos contemporáneos, como Rosenzweig, Buber o Lévinas ${ }^{13}$. Esto, sin duda, se da sin fatiga ni solución de continuidad a lo largo de toda la peculiar vocación literaria de Borges, y de allí su recurso continuo al encuentro, casi entrelazamiento, de su propio ser con el de un sin fin de sujetos, expresamente convocados por su poesía, muy diferentes y heterogéneos. Así le ocurre, en la antología, con las figuras del general Quiroga, Conrad, Homero, Milton, Groussac, el coronel Francisco Borges, Ariosto, el buen ladrón, el coronel Suárez, Cervantes, Spinoza, Joyce, Browning, Shakespeare, su propio padre, Heráclito, Endimión, Bürger, Kafka, etc. Esto, le sucede igualmente con los personajes ocultos tras determinados rótulos de sus poemas, como los de: "La noche que en el sur lo velaron", "A una sombra de mil ochocientos noventa y tantos", "Un viejo poeta", "A un poeta menor de 1899", etc.

En la obra, la identidad misma se transforma en una búsqueda, entre las figuras de los otros, creadora y llena de honestidad existencial en sí misma, por cuanto provoca una sincera, profunda e incesante auto-reflexión, una curvatura sobre sí mismo por parte del autor. El anhelo de su entretejerse con unos y otros hilos, y el de su confuso desciframiento, originan un movimiento que parece alejarse, pero que al cabo vuelve sobre su punto de partida, en torno a un yo misterioso y elusivo. Esto sólo cabe aguardarlo cuando el poeta se transfigura a sí mismo en filósofo, en alguien que alcanza a tomar una sabia distancia de sí, sin quedar por ello alienado o enajenado, distante en exceso de su busca. El poeta se convierte en filósofo, sin dejar de ser poeta, y las figuras de ambos se aúnan en un único ser, si bien oscilante, dubitativo e intermitente. Tal vez, una figura, en parte semejante, en este sentido, que resulte fecundo conectar con este particular asunto sea la de la pensadora-poeta María Zambrano ${ }^{14}$. En ella, encontramos también una profunda intersección entre lo poético y lo filosófico que orienta la propia subjetividad como vocación de originalidad y creatividad personales, cual

\footnotetext{
${ }^{13}$ Cf. Díaz, C., "El alba: el sí mismo y el otro que hay en el yo personal”, cap. XII ("La noche, el alba, el día”), en El Nuevo Pensamiento de Frank Rosenzweig, Salamanca, Ed. Instituto Emmanuel Mounier, colección Persona, no26, 2008, pp. 134 y ss.

${ }_{14}$ Zambrano, M. Obras Completas, Barcelona, Galaxia Gutemberg, vol. I, III, IV, VI. 2011, 2014, $2015,2018$.
} 
sucede en Borges. Aunque, en el caso de Zambrano, su camino o método característico alcanza toda una consistencia filosófica, gracias a su conocida clave de la razón-poética, cuyo célebre texto-Claros del bosque- ejemplificó de un modo magistral ${ }^{15}$. También posee esta autora otros puntos en común con la singular senda borgiana hacia el sujeto, como por ejemplo la centralidad que ella otorga a la vía del corazón, a ese pensar-vivir siempre la identidad personal desde lo más hondo del corazón.

La intersección anterior, empero, ocurre en Borges de un modo propio y característico. Para empezar, no sucede tanto a través de un alter ego ficcionado y fragmentado en múltiples yoes, como acontece, por ejemplo, en el Juan de Mairena o, más aún, en "Los doce poetas que pudieron existir" en De un cancionero apócrifo de Machado ${ }^{16}$. Más bien, en nuestro texto, asistimos a la experiencia de un cierto hiato inicial, operado poéticamente en el sujeto, a través del encuentro con el otro, que luego sin embargo parece regresar circularmente al punto de partida, envolviendo al yo, cual un bucle o remolino en la cuestión de la identidad. Esta experiencia, propiciada por la poesía de Borges, tiene interesantes semejanzas acaso con el ambivalente intercambiarse de sus recíprocas posiciones por parte de Unamuno y su rebelde protagonista en Niebla ${ }^{17}$; o a lo descrito, en los certeros análisis fenomenológicos de la identidad desde la hermenéutica de lo literario y artístico, desarrollados por Ricoeur ${ }^{18}$. También, parece tener ciertos puntos en común con las inquietantes experiencias de las que trata Foucault en Las palabras y las cosas, quien de hecho afirma, en su prefacio: "Este libro nació de un texto de Borges"19. Foucault estima que la relación de las cosas con el lenguaje, la expresión artística o las ciencias puede leerse en clave de una cierta forma de vaciamiento del sujeto, como ocurre en su reflexión en torno a "Las meninas", en la que este pensador interpreta ese desdoblamiento subjetivo del cuadro entre el rey y el pintor como la gestación de un espacio nulo que separa o excluye el encuentro intersubjetivo pleno. Ahora bien, aunque el punto de partida -este originario desdoblamiento o extravío del sujeto- acaso pueda resultar común, Borges se distancia, al cabo, tanto de su disolución estructuralista o de-constructora ${ }^{20}$, como de la aniquilación del sujeto mismo. El poeta redimensiona, desde una honda humildad, el peso de lo individual en la

15 Zambrano, M. Claros del bosque, Barcelona, Seix Barral, 1977.

${ }^{16}$ Cf. Machado, A.: "Los doce poetas que pudieron existir", en De un cancionero apócrifo, Poesías completas, Madrid, Espasa-Calpe, 1980, pp. 402-409.

17 Unamuno, M.: Niebla, Madrid, Espasa, 2006.

18 P. Ricoeur, Soi-même comme un autre, París, Éditions du Seuil, 1990.

19 Foucault, M.: Las palabras y las cosas, Siglo XXI, México, 1985, p. 1. Foucault se refiere, en concreto, a Otras inquisiciones, Buenos Aires, Emecé, 1960.

20 Derrida, J.: La escritura y la diferencia, Barcelona, Anthropos, 1989. 
creación artística y en la configuración personal. Pero, a la vez, jamás deja de referir y de referirse al yo, nunca se fatiga en la persecución de una subjetividad más rica o fecunda, ya sea para sus personajes, sus prójimos o sí mismo. Así, finalmente, su propia obsesión por una identidad y una vocación más o menos logradas y fecundas constituye un testimonio de este afán incansable en torno a la subjetividad humana. De esta forma, Borges es y será siempre un humanista, y su minuciosa arqueología poética no desintegrará lo antropológico, por cuanto reivindica siempre de algún modo lo humano, desde el fondo de lo humano mismo. Ello, por ejemplo, a través de esta interrogación en torno a la subjetividad, en cuanto diálogo perpetuo entre el mismo y el otro; así como por medio de la propia pregunta del poeta acerca de un incógnito sentido, en la exploración de las perplejidades suscitadas por la existencia, la cultura y la identidad.

Por otra parte, nunca el lector tiene, a lo largo de este poético -creativo- caminar tras la subjetividad, siempre nuevamente recomenzado por Borges, la impresión del engaño. No asistimos a una manipulación a través del lenguaje y la palabra de las identidades, a una especie de farsa más o menos lograda, a un mero fingimiento sin pausa ${ }^{21}$. De entre las sombras del sujeto, asoma siempre un anhelo auténtico, una cierta honestidad del autor, en este rastrear los signos y las huellas. Aquí, la indagación iniciada a partir de unas acaso borrosas o herméticas señales de identidad, se acompaña de la auto-reflexión que provocan las ideas mismas; estas parecen agitarse inquietas en el fondo del poema, cual buzos sumergidos en busca de una identidad más honda, entre las espesas y tormentosas aguas de la subjetividad. La identidad es, entre estos versos, un río al que enriquecen afluentes no sólo externos y ajenos, llegados de lejos, sino corrientes internas o subterráneas que nutren su fondo desde ocultas vetas propias. Se despliega como una subjetividad que es búsqueda filosófica-poética profunda del yo, una tarea ética de signo también claramente reflexivo, que se ve reclamada por la autenticidad y la hondura del propio ser personal. Para ello, pensamiento y creatividad, reflexión y belleza, constituyen los dos remos, las dos alas de este singular vuelo del poeta que, en figura de pensador, se levanta del nido de su yo tras la huidiza sombra de un sujeto más hondo. Borges aparece en cierta forma como un hermeneuta de su propia identidad y de la de quienes se entrecruzan en el tupido sendero desbrozado hacia su centro; esto, en el sentido más genuino de esta noción, en un intérprete en todo su alcance filosófico, en el mensajero de una comprensión más rica y profunda ${ }^{22}$.

\footnotetext{
${ }^{21}$ Del fenómeno de la manipulación por medio del lenguaje ha tratado López Quintás. Cf., por ejemplo, López Quintás, A.: La revolución oculta, Madrid, PPC, 1998.

22 Gadamer, H.-G.: Verdad y Método (I), Salamanca, Sígueme, 1977.
} 


\section{El yo, el otro del espejo y el sentido}

EL Yo CONSTITUYE un asunto omnipresente en la antología. El término "yo" resulta un dato incontestable, que asoma desde gran número de los rincones de estos versos, cual un tenaz motivo que se negara a abandonarlos. Esta reiterada presencia que, desde ellos, nos acompaña, toma diferentes formas y proyecta variados reflejos. Acaso, uno particularmente relevante y frecuente es el de la interrogación acerca de sí mismo, el del yo que se hace pregunta de sí, el yo que cuestiona en torno a sí. De esta manera, ya en el cuarto poema de la selección ("Líneas que pude haber escrito y perdido hacia 1922") se contiene el yo explícitamente, en forma de pregunta: "(...)/_soy yo esas cosas y las otras/". En "Cuarteta", el sujeto se interroga sobre su propia desaparición: "iEs posible que yo,.../ muera como murieron...l". E incluso Borges llega, en cierto instante, como reflejo de esta inquietud continua acerca de sí mismo, a escribir su mismo nombre en el interior de uno de los poemas: “(...)/espacio y tiempo y Borges ya me dejan/" (en "Límites"). El nombre y el yo habitan asimismo en muchos otros lugares de la antología, casi excesivos para ser aquí reseñados. Un caso significativo es el de pieza "Endimión en Latmos", donde la primera palabra que abre la composición es literalmente "Yo", y donde además se escribe: "(...)/y su infinita voz dijo mi nombrel". En otra ocasión, queda explícita esta interrogación, que persigue al poeta como un misterio indescifrable en la mayoría de sus versos: "Para ti ni siquiera soy un eco;/para mí soy un ansia y un arcano,/".

A lo largo de esta búsqueda creativa en torno de su yo más profundo, Borges acude a un objeto material, pleno de simbolismo y de fuerza de evocación para él. Este objeto posee, en su lírica, el poder de reunir al yo y al otro de una emblemática forma. Se trata de esa obsesiva realidad que se halla para Borges en el espejo. El espejo siempre es en Borges un elemento misterioso, digno de toda la atención. Ante él, el autor experimenta a la vez admiración y temor. Pero, además, el espejo va tener unas connotaciones muy importantes en relación con la identidad personal. Esto, por cuanto el espejo obra un prodigio o milagro inquietante, ya que desdobla al sujeto. Borges indaga, así, a través del mismo y de su metáfora, en torno a este desdoblamiento inevitable de la persona y a su raíz, que emparenta con el tiempo, los otros y la creatividad misma. No es, desde luego, con ello, a buen seguro, el único autor que ha recurrido a este peculiar objeto en busca del conocimiento del yo. Por citar sólo un pensador contemporáneo, también lo hizo Aranguren: "Se es persona porque se lleva el espejo -más o menos favorecedor, más o menos crítico- dentro de sí. Espejo parlante, que nos permite vernos (casi) como vemos a los otros, como si fuéramos, ya lo dije en latín, otro yo" 23 .

${ }^{23}$ López Aranguren, J. L.: "El Yo, el sí mismo, el otro y El Otro", en El otro, el extranjero, el extraño, Madrid, Revista de Occidente, número monográfico, no 140, enero (1993), p. 9. 
El juego-pregunta del espejo acerca del yo se transforma, en Borges, en una cuestión, cargada de moralidad, por el sentido existencial del sujeto y de su aventura creadora. Un ciego ante el espejo, al que a su vez otro sujeto puede mirar, supone la imagen de esta desafiante y comprometedora pregunta. Se trata de la interrogación por el sentido de la vida entre la realidad y la idea, por el desarrollo de la propia identidad cual una ambigua presencia, advertida en medio de un sinfín de huidizas sombras. Además, las ideas del tiempo, de la vanidad y de la muerte, como dimensiones intrínsecas del humano devenir, acompañan este interrogar acerca del sentido de la experiencia vital, reforzando su alcance y su connotación moral. Sin embargo, un rasgo seguramente decisivo, en esta conversión de la identidad en búsqueda o anhelo de sentido, se localiza en la creatividad. Creatividad que no es aquí simple invención de una u otra subjetividad, que no es tampoco sólo la mera expresividad del yo. La creatividad, como rasgo profundo y radical del propio ser moral del sujeto, es la llave que abre a este hacia una búsqueda permanente, siempre inagotable, plena de fértiles ramas y derivaciones. La verdadera cuestión es cómo puede el sujeto humano crear, aunque sea pobre y modestamente, arraigado en lo que le afecta más íntimamente; qué herencia misteriosa es esta de la creatividad que, a la vez, socava y fecunda el propio afán por determinada identidad, desde dentro de ella misma.

Borges rebajó las expectativas que otros pusieron en la capacidad creadora del ser humano en relación con lo literario. Afirmó que creamos, pero nunca desde la nada, y que nuestra originalidad es en gran medida un simple desarrollo a partir del legado de otros. Ahora bien, aun así, él postuló, poética y filosóficamente, el valor inmarcesible de la vocación personal del individuo ${ }^{24}$, y el hecho de que las facultades creativas humanas constituyen en cierta forma un camino ineludible de nuestro ser. Ello, dado que, como hemos visto, para nuestro escritor, la propia identidad personal se transfigura en una fecunda labor creativa y ética de búsqueda del sí mismo. Esto, aun en medio de un mundo que comporta un complejo laberinto de espejos, de otros, de sueños, de afectos, de ficciones y narraciones entrecruzadas. Con esta meta, al servicio de una fructífera indagación en torno a su más hondo yo, la viva creatividad de Borges invoca, ante nuestros ojos, en sus poemas, la presencia de un sinfín de seres. Estos provienen del más variado origen, ya sea este el presente, el futuro o el pasado, ya surjan de la vida o de los libros. Todos ellos actúan de un inquietante modo como signos de interrogación, entre los que aparece situado el sujeto, y cual símbolos de una realidad que nos visita desde un inalcanzable origen. Así, entre esta colección interminable, cabe recordar realidades como los laberin-

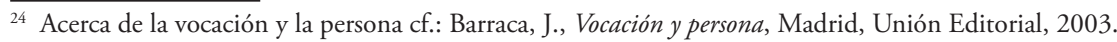


tos, el olvido, la muerte, los paredones, los cuchillos, la vanidad, el desencanto, las cárceles, el minotauro, la tristeza, las sombras, el reloj de arena, los asesinos, la noche, los sótanos, la guerra, etc. Pero, también, al mismo tiempo e intercalándose con estos, de la mano de Borges, no dejarán de visitar nunca al lector: los espejos, la memoria, los libros y bibliotecas, la gratitud, las estrellas, la ironía, los ríos, los sueños, la emoción, la luna, la belleza y la serenidad.

\section{Niveles de realidad, meta lenguaje y meta identidad}

UN RASGO DE ENORME HONDURA Y RIQUEZA, en la dimensión filosófica de la poesía de Borges, recorre la antología citada de parte a parte. Se trata del ya consabido tema del meta lenguaje, muy querido a Borges. Según este, se da un poema acerca del poema, una poesía de la poesía, una composición dentro de la composición que la encierra y a la vez la lanza desde su mismo interior hacia lo infinito. Nuestro autor, además, hace girar este tópico sobre el eje del sujeto, centro de su literatura y pensamiento poéticos en el volumen.

Borges abre siempre su literatura al asunto de los diversos niveles de realidad, que se encuentran entre sí enigmáticamente, superponiéndose o entrelazándose sin pausa. Este juego da lugar a una meditación permanente en torno al sentido, engendrado por la mutua interacción entre una lógica y su correspondiente meta lógica, un conocimiento y un conocer de aquel, etc. Ahora bien, en su poesía esto alcanza de lleno al sujeto. Un poema de la antología que ofrece un elocuente testimonio de esta meta lógica, transformada en meta identidad es "Ein Traum". En él, tres sujetos -ella, Kafka y el amigo de este- se mueven simultáneamente en un escenario donde se dan al menos dos niveles de realidad diversos, aunque concomitantes, que se vinculan e intercambian entre sí, hasta fundirse en la nada. Así: "/El hombre le contestó: Si pecamos, / Kafka dejará de soñarnos/". Además, este encuentro de dimensiones diferentes del ser se proyecta, pujante y misterioso, sobre la identidad, transformando al sujeto en un emisario de un proceso que lo incluye e interroga, sin límite preciso: "Kafka se dijo:/ Ahora que se fueron los dos, he quedado solo./Dejaré de soñarme/".

De este modo, en un juego de espejos y reverberaciones múltiples, de reflejos sin límite, asistimos a la gestación de un sujeto dentro del sujeto, un yo diverso en el yo. Ambos responden a niveles de lo real diferentes, pero no son meras ficciones lo que aquí se despliega, sino una subjetividad llena por este intercambio de perspectivas u ópticas. No son sólo mil nombres o sujetos posibles -como parece decirse en "Le regret d'Héraclite": "Yo, que tantos hombres he sido, (...)"-, sino algo más radical. Se trata de un sujeto nacido por el juego de niveles diferentes en torno del 
yo. Por un lado, se halla el sujeto originario y -por otro- el que lo contempla, por ejemplo, en el espejo; por una parte, se habla del muerto; pero, por otra, este parece integrarse en la existencia presente de quien le recuerda; y también sucede, de este modo, con las diversas figuras de la alteridad, reverberadas en la mente. Así ocurre en el "Poema de los dones": "(...)/suelo sentir con vago horror sagrado/ que soy el otro, el muerto, que habrá dado/los mismos pasos en los mismos días/".

Pero, tal vez, contemplar o ver no constituyen los verbos más exactos para expresar este nacer dentro, este gestarse -desde y sobre el propio yo- otro yo, igualmente mío, aunque diverso del primero. Pues la ceguera y oscuridad, en torno del ser personal, conviven en la interioridad, las vacilaciones de este saberse uno o el otro, se entrecruzan misteriosamente en este intercambio de sombras de la identidad, hasta forjar -en una dialéctica integradora- al mí mismo. De aquí, el que Borges logre, de una enigmática manera, superar la paradoja yo-otro que él ha generado en sus versos: "¿Cuál de los dos escribe este poema/de un yo plural y de una sola sombra?/¿Qué importa la palabra que me nombra/si es indiviso y uno el anatema?/”.

$\mathrm{Al}$ obrar, por tanto, gracias a la maravilla del lenguaje y de sus diversos niveles, esta síntesis de identidad-alteridad, en una nueva forma del sujeto, el poeta alcanza a engendrar una subjetividad enriquecida. Ello, ya sea esta literaria o real, pero siempre en la clave de la unidad en la diversidad, sin por esto fragmentar o disolver la individualidad o unicidad de la persona. En este punto de inflexión, se acerca a lo postulado por Buber, en su celebérrimo escrito Yo y tú, que precisamente se inicia con la afirmación de que el par "Yo-Tú" constituye una única palabra, capaz de integrar lo dual de sus distintos extremos, sin extraviar la carga de singularidad irreductible que "entre" sus polos alienta. ${ }^{25}$ Para lograr este peculiar efecto en la subjetividad, este movimiento simultáneo de distancia y cercanía con respecto al yo, que se descubre abierto por el otro desde dentro de su propia interioridad, Borges recurre con maestría al manejo del significado connotado por determinados objetos en su alcance simbólico. También acude, por supuesto, al propio prodigio que representa el lenguaje humano, y a la labor de una cierta hermenéutica de la identidad. Respecto a esto último, no puede extrañar que la palabra se convierta precisamente en el instrumento o palanca todopoderosos, empleados por Borges, para alzar al mundo, al discurso, al sujeto enteros, más allá de sí mismos, a través de un sucesivo ir del lenguaje al meta lenguaje o viceversa. Ya, desde muy antiguo, se ha advertido la facultad de la palabra para convocar distintos niveles de la realidad en torno de sí, como se observa en el mismo Cratilo platónico ${ }^{26}$.

\footnotetext{
25 Buber, M.: Yo y Tú, Madrid, Caparrós, 1993, trad. C. Díaz.

26 Platón: Cratilo o de la exactitud de las palabras, en Obras completas, Aguilar, 1990, pp. 508-552.
} 
En cuanto a los objetos, nuestro poeta acostumbra a acudir, entre otros, a los tres que siguen: al ya citado espejo, al juego de ajedrez y al mapa o plano. Del ajedrez, por ejemplo, extrae la idea de que la pieza -que representa a la persona- es movida por la mano del sujeto, quien a su vez es movido acaso por otro que le transciende, y así hasta el infinito. La estrofa final de "Ajedrez" así lo postula: "Dios mueve al jugador, y éste, la pieza/. ¿Qué dios detrás de Dios la trama empieza/de polvo y tiempo y sueño y agonías?/". En cuanto al mapa o plano, menciona el hecho de que este puede verse circularmente convertido en un dato de sí mismo, estar incluido dentro de su propia reproducción de lo real, cuando es completo, en una progresión de precisión que puede ir, de alguna forma, también hasta el infinito. Así lo explica es su glosa a ciertos versos de "Otro poema de los dones", en concreto a: "Gracias quiero dar al divino/laberinto de los efectos y de las causas/(...)/por la tortuga de Zenón y el mapa de Royce/". Ahora bien, en su nota a este poema, Borges aclara que: “(...) el mapa de Royce puede requerir una explicación”. Y, para darla, reproduce la idea de Royce: “(...) Ese mapa en tal caso debe contener un mapa del mapa, que debe contener un mapa del mapa del mapa, y así hasta lo infinito" ${ }^{27}$.

\section{Infinito, lenguaje y gratitud}

Memoria e identidad, desde luego, recuerdo y sujeto, pluralidad y singularidad, el yo y el otro, se aúnan en Borges en busca de este recobrar lo más hondo del ser personal. Si bien, es la magia del lenguaje poético, entreverado con el pensamiento, quien opera el prodigio de hacer presente y materializar, encarnar a este nuevo sujeto integrado. Brilla, aquí, en parte, el fulgor de esa facultad pragmática del lenguaje, en su dimensión ilocucionaria, de la que Searle trató al ocuparse de ese misterioso hacer cosas con palabras, cuando las cosas hechas no son ya simples enunciaciones o promesas, sino encuentros o alianzas sólidas, fuentes de verdaderas instituciones $^{28}$. Esto emparenta, así mismo, con las concepciones filosóficas que ven en el lenguaje un origen o manantial de la propia subjetividad personal, tal como postuló Benveniste, entre otros: "Es en y por el lenguaje como el hombre se constituye en sujeto; porque el lenguaje solo funda en realidad, en su realidad que es la del ser, el concepto mismo de ego" ${ }^{29}$.

Pero, además, para consolidarse renovadoramente, la identidad buscada parece, en la antología, querer escapar de su marco convencional, como si anhelase

\footnotetext{
27 Borges, J. L.: Antología poética 1923-1977, op. cit., p. 143.

28 Searle, J.: Actos de habla, Madrid, Ed. Cátedra, 1986.

29 Benveniste, E., Problemas de lingüística general, Madrid, Siglo XXI, 1971, p. 180
} 
transcender su nivel inicial, a través de este juego multidimensional. En él, se hace presente y patente una meta-identidad, una meta-subjetividad, tan característica de Borges, y que aquí alcanza una profundidad y fecundidad maravillosas, al proyectarse en forma poética sobre el sujeto. Los poemas "El centinela" y "All Our Yesterdays" constituyen dos hitos magistrales de esta reunificación y reintegración del sujeto, que se mueve entre los múltiples niveles de lo real, gracias a la vocación creadora que, desde dentro y desde fuera de él, lo va conformando, dibujando. Recordemos algunos versos a este propósito de "El centinela": "Está en mis pasos, en mi voz,/.../Advierto con fruición que casi no ve./.../Ninguno de los dos engaña al otro,.../Nos conocemos demasiado, inseparable hermano./.../(...) en la sombra ulterior del otro reino/estaré yo, esperándome/". Y, en "All Our Yesterdays", asistimos también al anhelo de una reunificación del sujeto en parte semejante: "Quiero saber de quién es mi pasado./¿¿De cuál de los que fui? (...)/.../Soy los que ya no son. Inútilmente/soy en la tarde esa perdida gente/".

Esto nos lleva a la consideración de un principio clave en la poesía de Borges, en torno a la propia identidad, en el libro que comentamos. Nos referimos a la alteridad radical, la del Otro con mayúsculas, como un cierto substrato de la subjetividad. La transcendencia que parece operarse en el sujeto, a través del juego entre los distintos niveles de la realidad, por medio del recurso al meta-lenguaje y la meta-lógica, acaba por apuntar hacia un origen situado más allá del límite de lo humano. El diálogo constante entre identidad inicial y cierta meta identidad, transparentado en el poema, señala hacia una profundidad más honda que la meramente finita. Es siempre una flecha, en este caso poética, que dirige nuestro afecto y atención, desde este sujeto transmutado en otro, hasta lo infinito.

$\mathrm{El}$ infinito, asunto permanente en la literatura de Borges, se nos revela como una clave decisiva asimismo de su poesía. $\mathrm{Y}$, en concreto, en una insinuación constante que abre -desde dentro- a la persona y la orienta hacia una fuente de sentido. Lo transcendente aparece gracias a este movimiento de encuentro y desencuentro, de cercanía y lejanía, entre el primer yo y otro yo más hondo, como un cierto horizonte. Esto no sólo podemos apreciarlo al reparar en las constantes alusiones metafísicas y metalingüísticas diseminadas entre los poemas, sino que se desprende del valor eminente que determinadas nociones desempeñan en muchos de los mismos. Entre ellas, deben mencionarse expresiones como: "una Realidad innegable", Arquetipo, esplendor, infinito, eternidad, Dios, divinidad, incesante, celestial, Cielo, "La Verdad", inmortal, Señor, inmensidad, el Otro, etc. Como se ve, la idea de ilimitación cobra aquí una pujanza extraordinaria, desde dentro del poema y a partir de sus concretos habitantes transciende a estos. En "Ajedrez" escribe: "(...)/Como el otro, este juego es infinito/". Y parece referirse, así, con la expresión "como el otro" a la propia existencia. 
El juego de lo infinito acompaña, pues, a Borges hasta el centro mismo de sus poemas, y se refleja en su lectura de la subjetividad como una realidad no clausurada en sí misma, sino abierta a lo que la supera indeciblemente. La subjetividad humana queda transfigurada, lanzada desde lo interior, a través de sus espejos, hacia lo que se sitúa más allá de ella sola. He aquí, por tanto, una realidad originaria más honda, perteneciente a un nivel de existencia diferente, que Borges llega a designar, en alguna ocasión, con diversos nombres emblemáticos inaugurados con letra inicial en mayúscula; realidad, en fin, distinta y que funda toda creatividad ulterior. De esta manera, el propio sujeto, su identidad y cuanto la alimenta, las cosas y los otros, resultan "dones", regalos inefables que nos hablan de un Otro con mayúsculas. La propia subjetividad es un enigmático regalo -el don de una irrenunciable pregunta por el sí mismo- que llega al yo desde una alteridad infinita. En definitiva, desde Otro, que se sitúa en el origen mismo del sujeto, cual una fuente sin principio, al modo levianasiano ${ }^{30}$. Aunque este dato no comporta unas u otras creencias, espirituales o religiosas, concretas en el propio autor. Lo que revela este lenguaje poético es sencillamente un infinito, obsequioso y misterioso, que ofrece cuanto enriquece la identidad, sin poder ser por ello prejuzgado o encasillado bajo una u otra categoría definidas. Leamos, sobre este proceso meta lógico de generación de identidades, los versos finales de "Ni siquiera soy polvo": "Para que yo pueda sońar al otro/(...)/mi Dios, mi soñador, sigue sonándome/".

En el don se halla un punto de inflexión capital para la reflexión en torno al sujeto a propósito de la obra. Esto, dado que cabe advertir que los dos poemas que sirven de eje central a la antología, y que de este modo la articulan - "Poema de los dones" y "Otro poema de los dones"-, constituyen justamente dos cantos, paralelos y entrecruzados, en cuanto al reconocimiento de una perpetua dádiva en relación con lo real y los humanos. Son, de hecho, dos himnos profundos y poéticos de acción de gracias por parte del sujeto ante lo más hondo que sí. En ellos, la clave se sitúa en la emocionada expresión de gratitud, por parte del poeta por los dones que ha recibido. Dones que nos refieren a un dador o donador sumo - "divino", le califica textualmente el poeta-, ya aparezca o no este de un modo más o menos explícito. Debido a esto, el nombre de Dios visitará, en ciertas ocasiones, aunque nunca con estridencias, sino suave y tiernamente, los labios del poeta, e insistimos en que ello no implica una u otra creencia concreta y final en su interior. Pero el dato cierto es que la expresión de la realidad de lo divino aparece con fiel asiduidad, y esto, con respeto e incluso fruición, hasta materializarse en una viva gratitud. Ello, a pesar de la dureza y amargor que, en el camino de la existencia, han también probado esos

${ }^{30}$ E. Lévinas, Humanismo del otro hombre, traducción G. González, Madrid, Caparrós, 1993. 
mismos labios del autor. De esto, ofrece un sublime y simbólico testimonio la conocida estrofa que da comienzo al "Poema de los dones", y que tanto se ha celebrado por su hondura y belleza: "Nadie rebaje a lágrima o reproche/esta declaración de la maestría/de Dios, que con magnífica ironía/me dio a la vez los libros y la noche/".

Así, la voz de Borges agradece su identidad entera, sin olvidar respecto a ella el misterio -insondable para él- de la ceguera, simbólica o real, propia o de sus personajes y compañeros, sobrevenida poco a poco durante la travesía poética y existencial. Tampoco excluye, de la herencia que comporta esta misma subjetividad, en un profundo gesto de humildad, a la tristeza de los más cercanos parientes y amigos que han contribuido a su forja, ni a la vecina e irrefutable muerte que aguarda solitaria al autor, ni a los fracasos o derrotas de próximos y lejanos interlocutores, ni a los dolores y desdenes personales entre los que se ha fraguado, lenta y siempre enraizada en el pasado (como la lluvia), esa inquietante e interrogadora identidad. Lo cierto es que, al obrar poética y filosóficamente así, la hermosa gesta de Borges, al hacer germinar su más lograda y agradecida identidad de entre sus limitaciones transcendidas, constituye un esfuerzo admirable. Esfuerzo que no resulta fácil para nadie, en nuestra acomodaticia y postmoderna sociedad, aunque muchos pensadores contemporáneos lo hayan reivindicado y aconsejado con vigor, como por ejemplo López Quintás ${ }^{31}$. Dar gracias por cuanto nos configura, a pesar de incluir en esto lo que nos cuesta o duele de nosotros mismos y de los otros, incorporar en esta gratitud nuestros sufrimientos y padecimientos, resulta una tarea identitaria difícil, mas llena de fecundidad, a la vez que una labor imprescindible para vivir con fertilidad como testimonió estremecedoramente Víktor Frankl ${ }^{32}$. Así, agradecer como un don nuestra identidad, al tiempo que participamos en el desarrollo creativo y fecundo de esta, desde nuestra originalidad, siempre constituye una ardua mas fructífera vocación personal, de acuerdo con lo revelado por pedagogos tales como J. Kentenich ${ }^{33}$.

La humildad se convierte, de esta manera, en otra clave luminosa de la singular interpretación que Borges realiza de su propia subjetividad. Esto conecta con la íntima vinculación entre la virtud de la humildad y la maduración fecunda de la subjetividad que se ha establecido, por parte de algunas meditaciones actuales acerca de este asunto. ${ }^{34}$ Entre los poemas borgianos, siempre palpita un corazón de algún modo menesteroso y atento a los otros, que sabe cuestionarse a sí mismo, que en un ejercicio sin término de humildad se interroga en torno a las raíces y sentido de su

\footnotetext{
31 López Quintás, A. Descubrir la grandeza de la vida, Estella, Ed. Verbo Divino, 2003.

32 Frankl, V. El hombre en busca de sentido, Barcelona, Herder, 21 a ed., 2001.

33 Kentenich, J. Textos pedagógicos, Santiago, Ed. Nueva Patris, 2008.

34 Barraca, J.: Vivir la humildad: ensayos contra la soberbia, Madrid, Ed. San Pablo, 2011.
} 
propio ser, sin la fatuidad ni el engreimiento que lo abocaría a una autoafirmación egolátrica y estéril. La humildad se palpa, verso a verso, en la característica lectura operada por Borges de su propia identidad, en cuanto este la experimenta como una acuciante, tentativa búsqueda sin término. Esta virtud abre dicha identidad al encuentro con los otros; la proyecta, desde una fecunda creatividad que se sabe en deuda con lo real y lo poético; la transciende, por medio de una reflexión abierta por el fascinante espejo del meta lenguaje, en cuyo fondo resuena la voz de Otro; $y$, al final, la transfigura, en la forma de una honda gratitud, que permite recuperarla integrada por todos los diversos afluentes que, en ella, misteriosamente, han convergido.

\section{Conclusiones}

La ANTOlogía Borgiana respira, desde su inicio, el aire de la filosofía. Lo hace con unos pulmones que van más allá de la cita erudita de numerosos pensadores, antiguos y modernos. Ideas filosóficas, de extrema profundidad y de egregio abolengo histórico, comparten espacio, entre sus versos, con una serie de hondas inquietudes metafísicas, antropológicas e incluso éticas, características de nuestro autor. En medio de todo ello, emerge una interrogación constante del poeta en torno a su propia identidad, y esta interrogación adquiere una figura decisiva en la obra.

Conviene acordar con Borges en la importancia de revivir en persona la pregunta por la propia identidad, de un modo permanente, y ello no sólo teorética sino existencialmente. A este respecto, una enseńanza capital de la antología estriba en que es preciso acertar a revivir la cuestión de nuestra subjetividad siempre creativamente, con fecundidad, con belleza, de acuerdo a lo que experimentamos a través de los fértiles poemas del autor. La cuestión de la identidad se proyecta, en la obra, gracias a una creativa serie de elementos literarios y filosóficos, que contribuye a dotarla de la original perspectiva borgiana, de su sello y marchamo característicos. Se trata de una inquietante conjunción de objetos y realidades, entre los que adquieren un valor crucial seres como los espejos, los libros, la memoria, los muertos, las palabras, los mapas, la noche, los ríos o los sueños. El sujeto que Borges nos revela es, por tanto, un ser en permanente busca de sí, pero en cuyo camino se cruza desconcertante, misteriosa y providentemente, el otro. Este otro no es, en un primer momento, la alteridad radical, ni un extranjero absoluto, sino una desconcertante figura del yo, venida desde un lugar diferente, desde otro nivel de lo real, aunque jamás ajena o lejana del todo a este yo en su sentido más profundo. Se traba así un encuentro o diálogo, lleno de vacilaciones, pero a la par de hondura y de fecundidad, entre dos 
yoes que terminan conformando un único ser. Este sujeto aunado, síntesis de experiencias propias y de vivencias de extraños compañeros de viaje, resulta el auténtico yo en su madurez, la persona enriquecida o desarrollada fértilmente, que ha crecido a través de la existencia misma y de los múltiples encuentros celebrados consigo misma, gracias a las cosas y a los otros. Esto, sucede, en Borges, en el evocador contexto de un mundo poblado de otros muchos mundos, en un universo habitado por universos distintos, en un desconcertante escenario en que se intercambian sin cesar diversos niveles de realidad, discurso y lenguaje. La persona fecundada por estos interiores encuentros, sin embargo, según el poeta, no vive clausurada en sí, no se halla cerrada en torno a su intimidad, cual un cepo. Los versos hacen audible la hermosa voz que rompe o abre esta subjetividad, hasta manifestarla herida y gozosa, aunque inefablemente, por lo infinito. La dimensión de lo transcendente estalla así en el sujeto poéticamente, salpicando de ilimitación el lenguaje, la memoria, el Arte, las experiencias, la existencia, los vínculos, la conciencia, el afecto. Ahora bien, resulta digno de admiración y aprendizaje el que esa ilimitación -que, como fuente enigmática, surge, en el sujeto, desde las cosas, las personas, el mundo y los días- siempre sea acogida con una honda gratitud, por parte del poeta. Este agradecimiento sabe leer las vivencias más diversas, y a veces incluso irónicamente crueles, como dones. De manera que el propio sujeto se sabe a sí mismo don, en su más honda intimidad, se capta como originalidad engendrada por quien es verdaderamente Origen de todo. Esto lo hace con la sencillez y la serenidad que sólo los interiores más honestos alcanzan. El poeta vive, en fin, el misterio de su identidad transcendida con una palabra agradecida, emocionada, humilde. 


\section{REFERENCIAS BIBLIOGRÁFICAS}

AA. VV. Ética y subjetividad: lecturas de Emmanuel Lévinas, G. González Rodríguez-Arnáiz (coordinador), Madrid, Ed. Universidad Complutense, 1994.

Azaovagh de la Rosa, A. "Judith Butler y su precariedad metódica", en: Bajo Palabra: revista de Filosofía, época II, no22, Madrid, pp. 147-170, 2019 (DOI: https://doi.org/10.15366/bp2019.22.007).

Barraca, J. Originalidad e identidad personal, Madrid, San Pablo, 2017.

Barraca, J. Vivir la humildad: ensayos contra la soberbia, Madrid, Ed. San Pablo, 2011.

Benveniste, E. Problemas de lingüistica general, Madrid, Siglo XXI, 1971.

Borges, J.L. Poesía completa, Barcelona, Destino, 2009.

Borges, J. L. Antología poética 1923/1977, Madrid, Alianza, 1981.

Buber, M. Yo y Tú, Madrid, Caparrós, trad. C. Díaz, 1993.

Ferrer, U. ¿Qué significa ser persona?, Palabra, Madrid, 2002.

Foucault, M. Las palabras y las cosas, México, Siglo XXI, 1985.

Frankl, V. El hombre en busca de sentido, Barcelona, Herder, 21ª ed., 2001.

Gadamer, H.-G.: Verdad y Método (I), Sígueme, Salamanca, 1977.

Gadamer, H.-G. Estética y hermenéutica, Madrid, Tecnos, 1996.

Derrida, J. La escritura y la diferencia, Barcelona, Anthropos, 1989.

Díaz, C. El Nuevo Pensamiento de Frank Rosenzweig, Salamanca, colección Persona, n²6, Instituto Emmanuel Mounier, 2008.

Iglesia, Anna María. "La poesía de Borges: una ficción autobiográfica”, Rev. Forma, vol. 2, pp. 69-81, 2013.

Kentenich, J. Textos pedagógicos, Santiago, Ed. Nueva Patris, 2008.

Lévinas, E. Humanismo del otro hombre, traducción G. González, Madrid, Caparrós, 1993.

López Quintás, A. La revolución oculta, PPC, Madrid, 1998.

López Quintás, A. Descubrir la grandeza de la vida, Estella, Ed. Verbo Divino, 2003. 
Maceiras, M. Identidad y responsabilidad, discurso de apertura del curso académico, Madrid, Universidad Complutense de Madrid, 1994.

Machado, A. "Los doce poetas que pudieron existir", en De un cancionero apócrifo, Poesías completas, Madrid, Espasa-Calpe, pp. 402-409, 1980.

Pessoa, F. Fernando Pessoa. Poesía, Madrid, Ed. Alianza, 1983.

Platón. Cratilo o de la exactitud de las palabras, en Madrid, Obras completas, Aguilar, 1990.

Ricoeur, P. Soi-même comme un autre, París, Éditions du Seuil, 1990.

Searle, J. Actos de habla, Madrid, Ed. Cátedra, 1986.

Unamuno, M. Niebla, Madrid, Espasa, 2006.

Viñas Piquer, David. "Recorrido fugaz por la poesía de Borges", Valparaíso, en Rev. Signos, v.32 n.45-46, pp. 57-70, 1990.

Zambrano, M. Claros del bosque, Barcelona, Seix Barral, Biblioteca Breve, 1997.

Zambrano, M. Obras Completas, Barcelona, Galaxia Gutemberg, vol. I, III, IV, VI. 2011, 2014, 2015, 2018.

DOI: https://doi.org/10.15366/bp2021.27.023

Bajo Palabra. II Época. No 27. Pgs: 443-464 